\title{
English Education Reform in Arab World
}

\author{
Rana Khan Mohammed Ishaq \\ Algonquin College, Kuwait
}

\begin{abstract}
Learning a second language always poses a challenge to learners. Arab learners have specific weaker areas and their problems need special consideration from English as a second language (ESL) teachers. This paper first aims to systematically discuss and deal in detail with the problematic areas that need attention. Arab learners show problems in communication and interaction. They lack fluency and feel shy in participating in class activities. Negative transfer from language one can hinder their learning and seriously affect the development of their productive and receptive skills. Secondly, some positive approaches have been suggested to minimize the effect of mother tongue interference on learning of English like guided step by step approach of the teacher to show the syntactic and semantic differences between the two languages. Contextual learning along with blended learning can also create the mood for young hi-tech learners, paving the way for the much-needed motivation for learning. ESL teachers need to tread cautiously and carefully while teaching English, as with a planned approach and perseverance, they can achieve their goals.
\end{abstract}

Keywords: blended learning, contextual learning, mother tongue interference

\section{Introduction}

Second language learning is always a challenge for any learners, and however, with concerted efforts and guidance of an efficient teacher this is not unachievable. Problems that learners face differ in each setting, and therefore, it is important that English as a second language (ESL) teachers analyze them and find a remedy for the same. Once the problem is diagnosed, it should not take long for it to be eradicated with self-invented and planned strategies to suit ones' students. English language learners just like any other second language experience various problems specific to the language.

English language learners in the Arab world are different and unique and need to be addressed in a special way. With the increased necessity of learning English worldwide, Arab learners are becoming aware, more than ever before, of their own need for acquiring proficiency in the language. English is the language of global communication and interaction as also the base language for learning major streams and acquiring the higher education for the majority of the learners worldwide. Arab learners are no different and are keenly pursuing proficiency in English but face problems unique to their background while learning the language.

In this paper, the author is going to investigate problems typical and distinct to Arab learners while trying to suggest remedies for the same in order to develop a theory based on studies and self-experiences. The author's conclusions and experiences have been supported and supplemented with information based on many pilot studies that have been conducted in this field. Researchers in recent studies at Arab Open University,

Rana Khan Mohammed Ishaq, Master of Arts, English Literature, English Instructor, English and Academic Foundations, Algonquin College, Kuwait. 
Lebanon (October 2008-March 2009) have noted that "ESL students in the first level of communication skills courses face difficulties in some aspects of listening comprehension, communicative ability in asking and responding to questions, using fluent English in class participation and producing academic English texts” (Khatib, 2009). The author fully agrees and will further address these issues and their remedies in this article.

\section{Problems Facing Arab Learners}

\section{Communicative Inability in Asking and Responding to Questions}

Firstly, Arab learners, in general, face problems in communicating in English. The reasons are manifold among which the most important could be the lack of environment to learn the target language. Most of the students are exposed to the language in schools or colleges and the teachers in the majority of the cases are non-native speakers, primarily Arabic speaking. This leads them to resort to the use of native language while instructing the learners. The exposure of English is limited to classrooms and that too is sometimes compromised. Moreover, English exposure to learners is devoid of the native speaking environment, which deprives them of the correct intonation and stress. While learning any language, practice is incumbent. In the case of Arab learners, most of the times are absent. English graduates hardly practice communicative skills due to lack of exposure even after they become teachers of the target language. Practice and exposure are very important for perfecting a language (Rabab’ah, 2016).

Secondly, lack of adequate knowledge of vocabulary can also hinder smooth communication for Arab learners. Poor knowledge of vocabulary coupled with improper usage leads to poor communication skills. English teachers often resort to first language (Arabic) in explaining the meaning of the new vocabulary and sometimes English literature (Rabab’ah, 2016). Consequently, learners experience difficulty in applying vocabulary while speaking. Also, it is believed that the best way to teach a foreign language is to teach the language in the language itself, and however, the teacher needs to be good enough for that (Halliday, McIntosh, \& Stevens, 1972/1984).

Finally, motivation also plays a major role in improving communicative abilities of a learner. Arab learners are generally aware of the importance of learning the English language, but that alone cannot persuade them to practice its skills unless they are truly interested and motivated to learn. Unfortunately, the majority of Arab learners are learning the language because they think it can advance their career goals or it might get them a good job. They lack the motivation to learn the language for its own sake or to be a part of the so-called “English- speaking community” (Seedhouse, 1996; Zughoul, 1987).

Due to the above-mentioned reasons, Arab learners feel shy or inhibited in asking questions or responding to questions being asked in the classes. They feel they might make a mistake and as a result, do not participate. This turns into a vicious cycle as they fail to participate which in turn weakens their communicative abilities.

\section{Lack of Fluency in Class Participation}

Arab learners typically have a problem in class participation. The reason clearly is a lack of fluency, due to which they fail to participate in various aspects of learning the language. This failure to participate could be in all the aspects of reading, writing, lexis, and grammar or as an isolated case with any one of them. However, in-class observations suggest that in most cases it is more in productive skills rather than receptive skills, and more so ever in speaking than in writing. This could lead us to understand that they do have the ability of expression but clearly lack the required spontaneous lexical knowledge needed at the time of speaking, just like 
any other language learner. In cases of Arab learners, with English, it is further worsened due to low motivational levels.

Background of EFL students also plays a major role in creating this paucity of fluency. The socio-cultural factors of EFL students are central to the problem where from the beginning they are taught to memorize their answers rather than learn the language. For this reason, when they enter college or university level where the language of instruction is English for studying medicine, engineering or business, they are at a loss to participate fluently in class discussions. English until now had been a subject for them and not a language of instruction (Ansari, 2012). The author's personal observations have also shown that Arab learners when they enter college or university level, they lack basic knowledge of syntax (parts of speech). As a result, the higher language levels become more difficult to them and they lose interest in the subject.

Also, there is a strong focus on reading and writing skills in Arab world whereas all the four skills in the English language are integrated and cannot be seen in isolation. Therefore, Arab learners focus only on reading and writing, as their main aim is to pass the examination. They forget that speaking and listening is equally important in real life (Ansari, 2012). The blame should fall on the teachers as well. The teachers skip listening exercises to lessen their burden. Listening skills are integral to language learning, as they set the correct model of language and pronunciation for the students to practice. According to Halliday, McIntosh, and Stevens (1972/1984, p. 16):

Oral mastery depends on practicing and repeating the pattern produced by a native speaker of the foreign language. It is the most economical way of learning a foreign language. ... When one has such a control of the essentials of the language he can almost automatically produce the usual patterns of that language.

This imbalance in teaching four skills develops hesitancy and shyness, which in turn is the real cause for lack of fluency in class participation.

\section{Problems in Producing Accurate Academic English Texts}

Writing is an essential tool that gives expression to a person's thought process. It is a process that involves various stages of thinking, planning, reviewing, editing, and making a perfect presentation finally. All these stages of writing require perfection in any language. Arab learners hence are required to think and produce academic texts like their native counterparts of English. However, they show serious limitations when it comes to producing academic English texts. Their work is usually riddled with pitfalls (errors/mistakes) which could be the result of inter-lingual transfer (resulting from language one) which will be dealt next in this article, or Intra-lingual interference which is due to the difficulties in the second language itself (Dulay \& Burt, 1982). Other types of errors could be developmental which are similar to a child learning a new language or ambiguous which result from both Inter-lingual transfer and developmental errors (Dulay \& Burt, 1982). Whatever be the reason or the type of error, they make common errors which are very distinct to Arab region and hence very unique.

Pitfalls usually result from inter-lingual transfer and could be in the form of errors or mistakes. There is a strong necessity to understand the importance of "error analysis" to gauge the problems arising in producing accurate academic English texts by Arab learners (see Figure 1). There is a difference between the two words errors and mistakes, though they appear to look the same. Any lapses and slips are considered to be performance related and hence mistakes, as they can be corrected. However, errors are systematic and are a result of incomplete knowledge on the part of the learner. These types of errors could be ingrained or fossilized 
with Arab learners of English. They are repetitive and exist usually due to lack of knowledge on the part of the learner. Thus, we can say that errors are either systematic (competence-based) or non-systematic (performance based), and hence, could be considered as mistakes which can be corrected by the learner himself with practice and time (Corder, 1986).

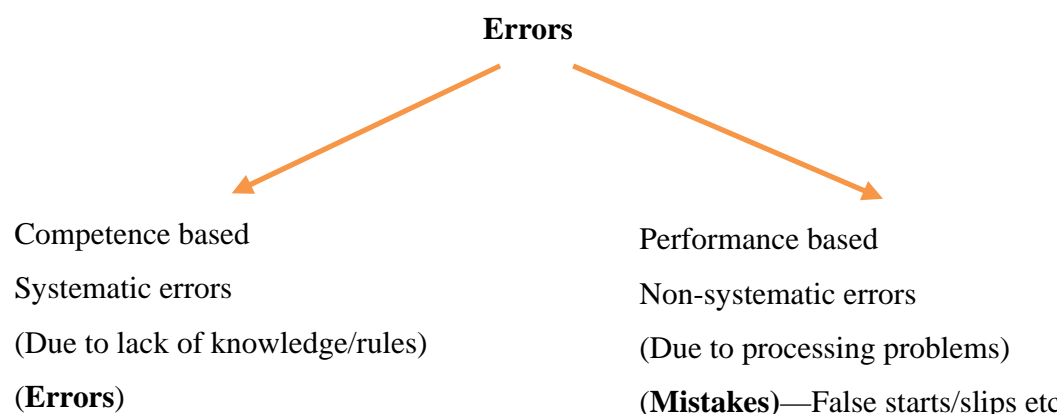

Figure 1. Error Analysis

When we talk about inter-lingual transfer, it could be syntactic or semantic. Various studies have revealed that these syntactic errors are more related to the use of prepositions, articles, and discourse markers. The incorrect use of prepositions is not a new problem. Any English teacher would love to share his/her problems that he has faced while teaching English. According to a study conducted by Tahaineh in 2010 at Princess Alia University College, the errors in the use of preposition made by 162 students were of three types - substitution, omission, and addition. The study revealed that Arab learners (Jordanians) specifically substituted in the following cases: "at" in place of "in," "between" in place of "among," "by” instead of "for," and "under” instead of "at." Tahaineh (2010) also discovered that Arab learners used correct preposition only if they had an equivalent in their mother tongue, however, they used incorrect prepositions if they had no equivalents. They also omitted prepositions if they had no equivalent in a typical situation and added one when they had an equivalent in their mother tongue.

Arab learners also used incorrect articles. According to Zughoul (2002), the Arab learners either delete an indefinite article, like "Lion is dangerous animal (a dangerous animal)" or substitute it for a definite article, like "Kuwait University had a grant from the state (had the grant)." They also substitute null article with indefinite article, like "A people buy food from the supermarket (people)." The study also revealed the use of definite article/indefinite article with marked plurals, like "Cell phones are misused by students in classes (students)." There were also cases of adjectives being used with indefinite article, like "She is a famous."

As mentioned earlier, it is important for second language learners to produce accurate academic English texts, but it is essential that they know how a discourse (spoken or written communication between people) is created by native speakers. Therefore, the knowledge and awareness of how discourse markers can significantly influence any written text is very important. According to Swan (2005, p. 151),

Some words and expressions are used to show how discourse is constructed. They can show the connection between what a speaker is saying and what has already been said or what is going to be said; they can indicate what speakers think about what they are saying or what others have said.

A study conducted by Modhish (2012) revealed that Arab learners extensively used inferential, causative, elaborative, and contrastive discourse markers. His work has given following conclusions: 
(1) Arab learners' use of discourse markers is usually limited to the ones which are known to them;

(2) In general, they resisted using unfamiliar discourse markers for the fear of making mistakes;

(3) They were obsessed with grammatically accurate texts, hence avoided using discourse markers so vital to producing coherent text;

(4) Their knowledge of grammar was also weak which further compelled them to make lesser use of discourse markers;

(5) Also, very little importance was given by teachers to discourse markers while teaching writing.

Thus, Modhish's (2012) study and such other studies have revealed that learners who used discourse markers appropriately produced better and coherent academic English texts (Jalilifar, 2008).

Errors could be semantic too when it comes to Arab learner's texts. Sometimes, Arab learners make errors which are grammatically correct and well-formed but they are wrongly placed in context (Brown, 2000). For example, an Arab Learner could respond like this, "I can read and write” to a question "Where do you study?" This is a grammatically correct and well-formed response but semantically inappropriate and out of context. There is a wide gap between what he interprets and what he utters. If Arab learners understood and interpreted correctly what they wanted to express, it would help them reconstruct correctly and make amendments.

\section{Target Language Errors Due to Mother Tongue Interference}

We can define mother tongue interference as the effect of language one on the learning of second or foreign language. Mother tongue interference occurs when a learner uses his own language as a reference for learning the second language. We cannot deny that Arabic is a richer language than English morphologically and different phonologically, which increases the difficulties for Arab learners as they tend to rely on their own syntax when it comes to following grammar rules. As referred in Wikipedia (2015), "Mother-tongue interference refers to the influence of the native language of the learner on his/her acquisition of the target language. What we mean by the target language is the language the learner is aiming to learn L2."

The transfer or interference of language one to language two can be explained by referring to two theories, namely, "contrastive analysis theory" and "error analysis theory." The contrastive analysis theory studies the similarities and differences between two languages in order to analyze the points and areas of errors. According to Wikipedia (2015), if the difference between the target language and the native language of a learner is big then the learner will face more difficulties in learning the target language as compared to a situation where the difference is small.

“Those items of a target language that are similar to the learners' first language will be easy for her/him to learn. And, those items of a target language that are different than the learners' first language will be difficult for the learner to acquire.” (Mazlan, 2015)

Interference of Arabic on the target language can be in learning any of the skills like reading writing, speaking or listening, or in learning linguistic aspects like syntax and phonetics. The main reason is when Arab learners usually start learning the English language their ground rules relating to their language one are already set. They cannot perceive English from ground zero since their knowledge of Arabic interferes in their learning the second language. They tend to perceive the new language from the same syntax, semantic, and phonetical rules as laid down by their native language.

Error Analysis theory on the other hand studies and discusses the errors of learners in the second language and tries to find reasons for such errors. These studies can be used to understand why learners of target 
language make errors and how language one can interfere in making these errors. In several cases, it has been noticed that Arab students tend to translate directly from Arabic into English without applying rules of English syntax hence they tend to make errors not only in prepositions and articles, but also in the use of discourse markers. For example, they would write "I am interested with it" instead of "I am interested in it." Such mistakes occur because Arabic prepositions follow different rules and as mentioned earlier in this article and Arab learners would use correct prepositions only if they had an equivalent in their native language or else they would omit or use wrong prepositions (Tahaineh, 2010).

Not only this, English article system is very different than the Arabic article system. The English language has a definite article "the" and indefinite article "a/an." On the contrary, there is no indefinite article "a/an" in the Arabic language. Arabic only follows definite article "Al” (Arabic expression for definite article - the) which confuses the Arab learners, and hence, they tend to use the definite article in places requiring usage of the indefinite article.

Arab learners make three types of errors in articles. Firstly, they tend to add the definite article at wrong places, like "I live in the Jahra" (no article required). Secondly, they omit articles where required and write, like "I study in college in Kaifan" (indefinite article "a” required) instead of "I study in a college in Kaifan.” The third error that Arab learners make is the omission of definite article at places, like "Banks are closed today" instead of "The banks are closed today." (Sabbah, 2015, pp. 269-288)

Another field where we find mother tongue interference is in the use of discourse markers. For example, it has been noticed that they tend to start a sentence with "because" and they do this when they have mentioned the cause in an earlier sentence. Therefore, their use of "because" as a connector is erroneous. This could be due to the use of similar words in their native language and their usage.

\section{Approaches Best Rewarded}

\section{Contextualized Learning}

Contextual learning is based on a constructivist, theory of teaching and learning. Learning takes place when teachers are able to present information in a way that students are able to construct meaning based on their own experiences (Wikipedia.org, n.d.).

Learners have a tendency to create mental pictures while they are reading and these pictures vary according to one's own background. What is important to note is that this visualization reflects their own experiences related to the topic that they are reading. They tend to connect with what they are reading and hence it helps improve their comprehension of the text if they can relate to it (Robertson, n.d). Therefore, a teacher of English can greatly increase and improve comprehension skills of his learners if the text is contextual to the learners.

Arab culture and literature are unique and we cannot possibly replace English curriculum with it, but we can definitely try to make the curriculum more culturally relevant to the learners. Each learner brings a world of experiences with him/her and an ESL teacher can do some research and help his/her learners connect with this diverse knowledge available to them in classrooms to build their own world of knowledge. It is very important that an ESL teacher builds up his/her own background knowledge of his/her students in order to help them relate to the topics and subjects they are learning in classes. This will not only motivate them to learn better, but also improve their performances in the target language.

Another way could be by inviting the students to contribute their ideas relating to a particular topic. They can be asked to participate in a class discussion by relating the topic to their own background and how it is 
close or different from their own socio-cultural background. Many times it has been noticed that some of the topics are entirely irrelevant to Arab culture and society which means the students are completely lost in comprehending them or relating to them.

At the same time, it is very important to consider that a student is comfortable discussing any such topics and sharing them with the rest of the class (Robertson, n.d.). Certain topics are sensitive and some cultures especially Arab culture has very different norms of living and behaving in public from the west.

Contextualization can be brought to class through art, music, and literature. Adult students whether they are Arabs or non-Arabs love to talk about music and it can be a big factor in making them talk about it. Students can be made to listen to any familiar or popular music and asked to translate its meaning into English if they are studying music in any of the topics in an English classroom.

Art can be brought into the classroom through various discussions on contemporary artwork, architecture, or any important events which are close to the topic of discussion being studied in class. Students can be asked to think and discuss if any such incidents or examples are found in their culture and how relevant the topic is to their culture. Students can also be asked to explore their literature and write about some famous literary works or authors if the topic being studied discusses literature. The inclusion of articles about Arab writers and authors will deepen their interest and motivate them further. These days more and more publishers are trying to bring multicultural texts in their publications. A wise selection on the part of an ESL teacher can significantly improve the learning environment in the classroom.

One positive consequence apart from motivating the students to learn more would be to promote mutual respect and awareness among Arab students about the similarities between their own culture and other cultures. This will further deepen their understanding of the text and subject as a whole.

\section{Fun Environment as a Catalyst for Motivation}

Motivation is crucial in an ESL class. Students who are motivated show better performance and a better pace of learning. How can students be motivated to learn? Fun factor can be a real catalyst for motivating the students. But first, we need to understand what we mean by motivation. Motivation can be defined as a concept used to describe the factors within an individual which arouse, maintain, and channel behavior towards a goal. Another way to say is that motivation is a goal-directed behavior (Naomen, n.d.).

Motivation has long been a problem for teachers of English. There are many ways students can be motivated to learn and fun factor as mentioned above is a real driving force. Arab learners can find ESL classes very boring if they are not motivated enough. The first step in this direction should be to lighten the atmosphere in the classroom. Any intelligent teacher would first try to create a friendly environment to get the students geared and charged for learning. There are a few things which can help lighten up the classroom environment like the seating arrangement which is friendlier and encourages group or pair work. Horseshoe arrangement or groups seated around a round table gives a perfect seating for a friendlier class. Students are encouraged to communicate with one another and collaborative learning is a natural boost for ESL students. An ESL teacher can also create the mood for fun by introducing various activities like grammar games and role plays which make learning fun and interesting. Story-telling and realia can further add interest to any ESL class.

Students always remember a teacher who was fun and treated them like a friend. Trust is what encourages students to get motivated and to develop that trust it is foremost for any ESL teacher to be a friend first and then a teacher. For some teachers, it is very natural to feel comfortable in their skin and carry themselves confidently. 
But, for some, it requires a lot of effort to be friendly in a class that does not speak his/her language. The best way is to be yourself and bring out the best in your personality to the classroom. It can be a good musician, painter, or a comedian. Students always like the informal side of their teacher to mingle with them and that puts their guard down and encourages them to communicate freely.

It is a good idea to bring a lot of drama to the classroom through role play. A wise teacher would customize role plays to suit the needs of his or her class. For example, if the class is primarily of housewives or women, it is advisable to ask students to create their own role-play comprising of housewives, instead of following one from the textbook that asks for a role play between two businessmen/sportsmen (BusyTeacher.org, n.d.).

A truly memorable ESL teacher would not waste any opportunity or a chaotic situation into something to laugh about later. A simple act to show or try to speak in their native language can create a light mood for them. Arab learners, for example, find it amusing when a foreigner (teacher in this case) speaks or tries to speak in broken Arabic or tries to fake an accent. They also find it interesting when their teacher would struggle with meaning in Arabic to explain some vocabulary in English. I have tried this trick many times to encourage them to correct me, which promotes unconscious learning. Whichever way we try as teachers, it has to be kept in mind that we always remember a teacher who was fun and friendly to be within the class and that we loved that particular subject the most.

\section{Blended Learning: A Perfect Engaging Tool for the Young Hi-Tech Learner}

Gone are the days when the teacher commanded the classroom and the students simply took notes. Today, a classroom is more interactive and collaborative, which should thank to the advent of blended learning approaches. Blended learning widely includes anything that involves computer-aided learning or the use of internet based devices or tools in the classroom along with conventional face to face teaching. What makes blended learning so essential in a modern day classroom? Young Learners are hooked and plugged-in to net and multimedia devices all the time and learning becomes all the more engaging and challenging when imparted through technology. It keeps them stimulated and engaged $24 \times 7$ (Khan, 2015).

Educational institutions worldwide have shown a shift in approach and this is due to the fact that blended learning incorporates and integrates traditional learning with online teaching (Tayebinik \& Puteh, 2013).

Blended learning shows a marked shift from the teacher-centered approach to a student-centered and more interactive approach, which offers materials anytime and anywhere. It not only motivates the students but also caters to the varying needs of learners in a mixed ability classroom. Blended learning can be best defined as an enriched, student-centered learning experience made possible by the harmonious integration of various strategies, achieved by combining face to face interaction with information and communication technology (ICT) (Torrisi-Steele, 2011, p. 360).

This definition offers three dimensions to blended learning namely the student-centered learning, the learning strategies and the tools of implementation (Alaidaroos \& Madini, 2016).

In-class observations have shown that students respond better in an e-classroom or blended learning environment. They are more focused and alert whenever a smart board or learning management systems (LMS) is employed for teaching. A sharp increase has been noticed in their performances when they are exposed to learning management systems, like Edmodo and Schoology. Learning management systems and applications (e.g., Edmodo) not only help students and teachers collaborate better but also help in keeping a track of their grades and progress in class. 
Blended learning has an advantage over conventional learning as it can be availed at the convenience of the learner leading to higher motivational levels. Learners can access study material when and wherever they need it in the classroom or at home. When there are no disruptions in learner's busy schedule due to his studies, he feels more driven and motivated. Usage of LMS for extra practice has given excellent results in ESL classes. Learners have availed them to their best advantage at their own convenience.

Every learner is different and needs personalization in the learning process. Due to time pressures and a higher number of strength of learners in classes personalized teaching becomes impossible. Blended learning ensures that learners can customize their learning experience to suit their needs and allows for better retention of content.

Classroom experiences have shown that students who followed their own patterns of learning with the aid of computer-assisted solutions showed better retention of content as compared to conventional classroom experiences and performances. Retention is an important factor in the learning process and blended learning reinforces and complements it. I have tried and tested this in my classes for teaching vocabulary.

Conventional classroom teaching is instructor-led and dominated. Students who are shy and introverted find it hard to mingle and interact with fellow students and the teacher. Blended learning, however, gives them the freedom to open up and give their best through various teaching techniques like chat rooms and discussion groups. Blended learning classrooms are more interactive in their approach, and hence, generate learner interest in discussions persuading them to participate in such discussions without their becoming conscious.

Oxford LMS successfully implements this practice of discussions which draws students onto a discussion board thus helping them to open up and express. This is further aided by the fact that instructors are not allowed to monopolize and dominate discussions just like a conventional classroom.

Modern classes have become hi-tech with the advent of computers. Students can now see multi-media presentations, clips, and images etc. with the help of i-tools and computers not only in the classrooms but also in the privacy of their home. Smart boards enable a better classroom experience as compared to old fashioned blackboard teaching enabling students to retain whatever is being taught in the classroom. The author noticed a big change in students since the day she started using i-tools and smart board for teaching the language. Using video clips for taught topics generated interest and discussion leading to higher levels of motivation in students.

Through a well-developed LMS tracking, student progress is a breeze. Students are given various tasks online which are a part of their grading process. Students participate in these tasks to improve their grades which in turn enhance their learning experience. Tracking student progress becomes a lot easier for a teacher as all the grades automatically come to the teacher, and he can conveniently monitor students on an individual basis.

Some students are shy and do not feel comfortable in a large group. They have problems opening up for the fear of making mistakes and especially if they find a particular task too difficult. Blended learning or e-learning gives such students, the freedom to tackle these situations in a risk-free environment without the fear of embarrassment in front of intimidating peers or an instructor. Blended learning alleviates their fears and guides them how to improve upon their performances.

We cannot overlook the fact though as teachers, that no learning is complete without the aid of conventional teaching techniques. Therefore, there is a need to have a balanced approach where the students have the freedom to choose the e-learning modes, they prefer, perfectly set in a conventional instructor-led teaching environment. In other words, blended learning is a perfect solution to a modern learning environment. 


\section{Guided and Pushed Output With the Tutor's Guidance and Encouragement}

Writing is often the last of all the four skills to develop. Why is it so? And to top it the students hate to write. It is a big challenge for any ESL teacher to motivate his/her students to write. It is very important for students to understand that writing is not only about producing accurate academic texts, but it is about expressing their ideas and putting them into words. They have to be encouraged to write without the fear of making errors. The vocabulary they should use does not have to be special. They can make a start with small sentences about day today contextual topics to make them write correct sentences to start with. It is a good idea to give them some helpful hints or useful language on the board to help them write.

However, it is very important to understand that in most Asian and Arab countries the practice is to write the final paragraph. The students don't have an idea that they need to plan and write. They are surprised if the teacher tells them that they have to brainstorm ideas and then organize and create a draft which follows a final writing after a review from the teacher. They are tuned to put their ideas to final shape and not to a draft. They have to be coaxed tactfully into writing a draft first through step by step approach and then encouraged to write. It is not an overnight job for a teacher and will take a long time before he can make his students write on this pattern, but the results are amazing.

But, before they start making sentences and follow the structural format of a paragraph, they need to understand the format of an error-free sentence. What goes into making a sentence or what are the inherent parts of a sentence? It is important for them to understand that noun and verb are the essential ingredients in a sentence. If anyone is missing they have an incomplete sentence. They also need to be shown the importance of punctuation and capitalization in a sentence (Seifert, n.d.). Many times students are pushed into writing without being explained or taught the basics of sentence formation resulting in sentences and paragraphs riddled with errors. This information can be presented to them in an interesting fun-filled presentation.

It is equally important to teach them the importance of coherence and cohesion in writing. In order to teach them coherence, they need to understand important constituents of a paragraph like the topic sentence, supporting sentences and the concluding sentence. They should be taught that a topic sentence introduces the main idea in a paragraph, supporting sentences build on that idea and the concluding sentence finally restates the main idea presented in the topic sentence. They need to be shown sufficient examples to be able to follow the structural format. If they learn to follow correct format there will be a consistency and coherence in their work. Teaching them the importance of discourse markers like linkers, transitions words and connectors is equally significant in terms of teaching them coherence and cohesion. Discourse markers are indispensable to ensure flow in any writing. They give flow to writers' ideas and thoughts and are crucial in providing consistency in their writing. Using visuals and power-point presentations can make this task easy for an ESL teacher (Seifert, n.d.).

Collaborative work and group work are essential features of an ESL writing class. Collaboration helps those students who are shy to come forward but contribute efficiently in a group. Students can be taught how to brainstorm ideas and create idea maps individually and in a group (Seifert, n.d.). Brainstorming ideas help them come up with great writings on any chosen topic. Collaborative or group work strategy helps slow starters eventually catch up with the help of other sharper members of the group.

Teaching them the significance of planning their work is very essential. They should be taught the value of planning in their writings and how it can help them save time wasted during the actual writing. They should be 
taught to plan their work in an outline consisting of introduction, body, and conclusion. Planning their work will show professionalism in their writing and perfect their work. Initially, they can be guided and instructed through visuals or presentations how to construct and plan outlines for their work. Handouts using graphic analysis to build ideas systematically with useful handy tips are also a good idea to give them step by step approach to writing paragraphs (Seifert, n.d.).

Choice of topics is one of the most important factors in making ESL students love writing tasks. (Seifert, n.d.). Generally, the topics chosen by teachers are very irrelevant and not at all contextual. Students lack the motivation to write on such topics. Choosing topics which are contextual and relevant can improve students' mood for writing tasks. Students can also be asked to contribute ideas for writing thus adding to their enthusiasm.

While keeping in mind the above mentioned approaches, it is very crucial to understand that none of them will make an impact if not followed systematically and in an organized manner. They have to be taught in flowing sessions following one after another, or else the teacher will have to backtrack every time in order to teach a vital part of a sequence.

\section{EFL Teacher's Role in Creating Awareness in Areas of Differences Between Arabic and English Syntactic Structures}

According to Corder (1967), "Making errors is an inevitable part of learning since people cannot learn languages without first systematically committing errors. Thus, they are different from mistakes which are unsystematic deviations.”

Mistakes can be corrected and are usually made by native speakers, but errors are ingrained and are due to the inter-lingual transfer of language one on learning of language two. Arab learners need careful handling if they are to be taught their inherent errors.

It has been found that grammatical errors committed by Arab ESL learners are primarily related to verbs, relative clauses, articles, noun modifiers, and prepositions (Al Buainain, n.d.). It is usually noticed that tense errors are due to negative transfer from Arabic as there are only perfect and the imperfect tenses in Arabic making it difficult for Arab learners to adjust to the concept of progressive and perfect tenses in English. Hence, they have a problem in distinguishing between present progressive and present simple tenses, as also in present/past perfect tenses with present/past simple tenses (Mukattash, 1978). If the teacher can make them aware of these errors they might try to avoid these errors with time.

One of the most noted errors is that of omission of the verb "be” like, "I joining the university this year." in the progressive tense or addition of it in simple tense- "She is eats her meals on time.” Arab learners also make subject-verb agreement errors quite a lot. This could be due to overgeneralization strategy like using "is" instead of "are" or "has" instead of "have" (Al Buainain, n.d.). Pedagogically, these errors could be avoided by telling the learners about these negative transfers from language one.

Arab learners also have a problem deciding if they need a definite article with a noun in a particular context. Findings also show that they tend to omit the use of indefinite article "a/an." This is due to the fact that Arabic system follows a very different article system. It has a different concept of definiteness and indefiniteness.

ESL teachers need to remember that they have to treat their students with sensitivity and consideration. They should aim at creating non-threatening classrooms where they can tell their learners that with diligence 
and patience writing can be learned (Zughoul, 2002). They need to make sufficient changes in their approaches to teaching grammar in such a way so as to eliminate the error by pointing to the learners the syntactic differences between the two languages.

Prepositions pose another negative transfer problem as studies show that Arab ESL learners choose wrong prepositions if they do not have equivalents in their mother tongue. They also tend to omit prepositions if their mother tongue does not require one in such a situation. Furthermore, they add prepositions if they have equivalents in their mother tongue and generally use correct preposition in such cases. Pedagogically, these learners could be taught to be careful when they make such transfers. They can be made aware of positive and negative transfers while teaching grammar (Tahaineh, 2010). Thus, identification of the problem could lead to designing new pedagogical strategies for teaching syntax to Arab learners and creating awareness in them to avoid such errors.

Discourse markers are an integral part of writing and need to be treated and tackled explicitly and implicitly by ESL teachers. Awareness of the use of discourse markers should be made an integral part of teaching writing to students. They should be made conscious of its importance in producing coherent and cohesive writing. A study in the contrastive analysis of discourse markers would definitely help teachers and learners alike in comprehending mistakes and errors produced during learning English (Tahaineh, 2010). The detailed contrastive analysis and error prediction can significantly improve the pace of instruction. The analysis of errors can considerably guide the teacher, and the teacher, in turn, can guide the learner in their progress of learning the language. Therefore students' errors are indispensable to teaching and prove to be a valuable feedback for teachers.

\section{Conclusion}

To conclude, Arab learners are consciously aware of their need for learning English and are making efforts to acquire the skills of the language. Arab learners face certain problems while learning English and ESL teachers have a special task and a goal to achieve with their concerted efforts. ESL teachers need to sufficiently motivate them to achieve their goals through fun-filled teaching in classes, blended learning, and guided, and pushed approach for better output in productive skills. In all this, the teacher's role is very crucial as a mentor and guide who is a friend first and teacher next. He/she needs to build mutual trust and rapport with his/her students, so that they are motivated to participate well in class activities and the learning process. No approach is easy, but with persistent effort and dedication, Arab learners can be coaxed to show better results both in receptive and productive skills along with an improved proficiency in second language learning.

\section{References}

Al Buainain, H. A. (n.d.). Researching types and causes of errors in Arabic speakers' writings. Retrieved from https://www. academia.edu/3002668/Researching_Types_and_Causes_of_Errors_in_Arabic_Speakers_Writing

Alaidaroos, K., \& Madini, A. A. (2016). Exploring EFL students' perception in blended learning environment in Saudi technical education context. International Journal of Educational Investigation, Volume 3, June Special issue, No.6: 69-81 ISSN: 2410-3446, 70.

Ansari, A. A. (2012). The teaching of English to Arab students: Problems and remedies. Educational Research, Volume 3, Issue 6. Brown, H. D. (2000). Principles of language learning and teaching. New Jersey: Prentice Hall.

BusyTeacher.org. (n.d.). ESL teachers ask: How can i be a more memorable teacher? Retrieved from BusyTeacher.org http://m. busyteacher.org/19123-how-can-i-be-more-memorable-teacher.html 
Corder, S. P. (1967). The significance of learners' errors. International Review of Applied Linguistics in Language Teaching? Issue 5, Page 161-170., 5.

Corder, S. P. (1986). Error analysis and interlanguage. Hong Kong: Oxford University Press.

Dulay, H., \& Burt, M. (1982). Language two. New York, N.Y.: OUP.

Halliday, M, McIntosh, A., \& Stevens, P. (1972/1984). Learning foreign languages. In R. Nasr (Ed.), Teaching and learning English, 19-20. Harlow: Longman.

Jalilifar, A. (2008). Discourse markers in composition writings: The case of Iranian learners of English as a foreign language. Retrieved from http://dx.doi.org/10.1016/S0378-2166(98)00101-5

Khan, R. (2015, November). E-learning: An indispensable feature of a modern classroom., TESOL Kuwait Newsletter, 2015, November issue, pp. 12-13.

Lado, R. (1957). Linguistics across cultures. USA: University of Michigan Press.

Mazlan, A. (2015). Contrastive analysis theory. Retrieved from http://ar.scribd.com/doc/129396815/Contrastive-Analysis-Theory \#

Modhish, A. S. (2012). Use of discourse markers in the composition writings of Arab EFL learners . English Language Teaching, 5(5), 56-61.

Mukattash, L. (1978). A pilot project in common grammatical errors in Jordanian English. Interlanguage Studies Bulletin, pp. 250-291.

Naomen, A. (n.d.). Ways of motivating EFL/ESL students in the classroom. Retrieved from https://www.teachingenglish.org.uk/ category/tags/http/teachingenglish-alexenoamenblogspotcom

Rabab’ah, G. (2016). Communication problems facing Arab learners of English. Research Gate, 180-194.

Robertson, K. (n.d.). Connect students' knowledge of content in the ELL cassroom. Retrieved from http://www.colorincolorado. org

Sabbah Salman Sabah (2015). Negative transfer: Arabic language interference to English learning. Arab World English Journal, 273.

Seedhouse, P. (1996). Classroom Interaction: possibilities and impossibilities. ELT Journal, 69.

Seifert, S. (n.d.). 7 powerful writing skills that will give your ESL students an edge. Retrieved from http://www.fluentu.com/ english/educator/blog/esl-writing-skills/

Swan, M. (2005). Practical English usage. Oxford University Press, Uk, 151.

Tahaineh, Y. (2010). A review of EFL Arab learners' language: Pitfalls and pedagogical implications. International Journal of English Linguistics, 4(1).

Tayebinik, M., \& Puteh, M. . (2013). Blended learning or e-learning. International Magazine on Advances in Computer Science and Telecommunications, 103-110.

Torrisi-Steele, G. (2011). This thing called blended learning: A definition and planning approach. In K. Krause, M. Buckridge, C. Grimmer, \& S. Purbrick-Illek (Eds.), Research and development in higher education: Reshaping higher education (Vol. 34, pp. 360-371). Australia: Gold Coast.

Wikipedia. (2015). Contrastive analysis. Retrieved from https://en.wikipedia.org/wiki/Contrastive_analysis

Wikipedia.org. (n.d.). Contextual learning. Retrieved from https://en.wikipedia.org

Zughoul, M. (1987). Restructuring the English Department in the third world universities: Alternative approach for the teaching of English literature. IRAL, 25(3), 221- 236.

Zughoul, M. (2002). Interlanguage syntax of Arabic-speaking learners of English: The noun phrase. (ERIC database ED 479649) 